\title{
Targeting the Wnt/frizzled signaling pathway after myocardial infarction: A new tool in the therapeutic toolbox?
}

Citation for published version (APA):

Daskalopoulos, E. P., Hermans, K. C. M., Janssen, B. J. A., \& Blankesteijn, W. M. (2013). Targeting the Wnt/frizzled signaling pathway after myocardial infarction: A new tool in the therapeutic toolbox? Trends in Cardiovascular Medicine, 23(4), 121-127. https://doi.org/10.1016/j.tcm.2012.09.010

Document status and date:

Published: 01/05/2013

DOI:

10.1016/j.tcm.2012.09.010

Document Version:

Publisher's PDF, also known as Version of record

Document license:

Taverne

Please check the document version of this publication:

- A submitted manuscript is the version of the article upon submission and before peer-review. There can be important differences between the submitted version and the official published version of record.

People interested in the research are advised to contact the author for the final version of the publication, or visit the DOI to the publisher's website.

- The final author version and the galley proof are versions of the publication after peer review.

- The final published version features the final layout of the paper including the volume, issue and page numbers.

Link to publication

\footnotetext{
General rights rights.

- You may freely distribute the URL identifying the publication in the public portal. please follow below link for the End User Agreement:

www.umlib.nl/taverne-license

Take down policy

If you believe that this document breaches copyright please contact us at:

repository@maastrichtuniversity.nl

providing details and we will investigate your claim.
}

Copyright and moral rights for the publications made accessible in the public portal are retained by the authors and/or other copyright owners and it is a condition of accessing publications that users recognise and abide by the legal requirements associated with these

- Users may download and print one copy of any publication from the public portal for the purpose of private study or research.

- You may not further distribute the material or use it for any profit-making activity or commercial gain

If the publication is distributed under the terms of Article $25 \mathrm{fa}$ of the Dutch Copyright Act, indicated by the "Taverne" license above, 


\title{
Review article
}

\section{Targeting the Wnt/frizzled signaling pathway after myocardial infarction: A new tool in the therapeutic toolbox?}

\author{
Evangelos P. Daskalopoulos, Kevin C.M. Hermans, Ben J.A. Janssen, and \\ W. Matthijs Blankesteijn*
}

Department of Pharmacology, Cardiovascular Research Institute Maastricht, Maastricht University, 50 Universiteitssingel, 6229ER Maastricht, P.O. Box 616, 6200MD Maastricht, The Netherlands

\section{A R T I C L E I N F O}

Article history:

Received 3 August 2012

Received in revised form

24 September 2012

Accepted 25 September 2012

Available online 21 December 2012

\begin{abstract}
A B S T R A C T
Wnt/frizzled signaling in the adult heart is quiescent under normal conditions; however it is reactivated after myocardial infarction (MI). Any intervention the various levels of this pathway can modulate its signaling. Several studies have targeted Wnt/frizzled signaling after MI with the majority of them indicating that the inhibition of the pathway is beneficial since it improves infarct healing and prevents heart failure. This suggests that blocking the Wnt/frizzled signaling pathway could be a potential novel therapeutic target to prevent the adverse cardiac remodeling after MI.
\end{abstract}

(c) 2012 Published by Elsevier Inc.

\section{Introduction}

Myocardial infarction (MI) occurs when a coronary artery is partially or completely occluded due to the presence of a thrombus, stenosis (due to atherosclerosis), or coronary spasm. If blood flow to the myocardium is not restored promptly then myocyte death is initiated, followed by a complex and long-lasting wound healing process that aims to compensate for the lost cardiomyocytes and sustain the pumping function of the heart (Cleutjens et al., 1999).

Early after the onset of MI, immune cells invade the injured myocardium, followed by a fibrotic process that occurs not only in the infarcted area, but also in remote areas (Cleutjens et al., 1999; Daskalopoulos et al., 2012). Remaining cardiomyocytes become hypertrophic and the infarct area becomes thin and dilates excessively. Consequently, the size and shape of the heart changes. Usually this adverse remodeling of the heart develops slowly and eventually may lead to heart failure (HF), especially when optimal pharmacologic treatment is lacking (Cleutjens et al., 1999; Gajarsa and Kloner, 2011). Approximately 1 in 5 people that suffer MI after 65 years of age, develop HF (Roger et al., 2012). The number of HF patients worldwide is estimated to be more than 23 million people (Bui et al., 2011) and about 6-10\% of people over 65 years of age suffer from it (McMurray and Pfeffer, 2005), establishing it as a major health problem.

Current pharmacotherapy of $\mathrm{HF}$ is targeting the $\beta$-adrenergic system, the renin-angiotensin-aldosterone system (RAAS) and the reduction of fluid overload (diuretics). Despite the availability of this toolbox, treatment of HF is not curative but mainly symptomatic and it can only delay the adverse cardiac remodeling and the progression of HF but not fully prevent them. Many drug discovery programs in the molecular signaling pathways that lead to HF have been initiated to find new

\footnotetext{
*Corresponding author. Tel.: +31 433881 344; fax: +31 433884149.

E-mail address: wm.blankesteijn@maastrichtuniversity.nl (W. Matthijs Blankesteijn).
} 
targets for treatment. While some of these pathways - such as the PI3K/Akt, the cAMP/PKA, the $\mathrm{Ca}^{2+}$, the JNK, the Jak/STAT, the NFKB pathways - have been extensively studied (Gajarsa and Kloner, 2011; Katz and Konstam, 2009), no major breakthroughs have been reported regarding their therapeutic value. The focus of this article is to review the potential of interventions in the Wnt/frizzled signaling pathway in the wound healing process after MI and their efficacy in the prevention of HF following MI.

\section{The Wnt/frizzled signaling pathway}

The first Wnt gene (int-1, later renamed to Wnt1) was discovered in 1982 in tumor studies (Nusse and Varmus, 1982). Since then, many reports have unmasked an essential role for Wnt/frizzled signaling in developmental processes. In normal healthy conditions, activity of Wnt/frizzled signaling is silent (Koval et al., 2011); however, after injury and in various pathologic states, repair processes are initiated, which comprise mainly developmental signaling pathways, including Wnt/frizzled (Clevers and Nusse, 2012).

The Wnt/frizzled pathway is subdivided into 2 branches. The canonical ( $\beta$-catenin dependent) pathway has been most extensively studied and is depicted in Fig. 1 . The stimulation of the Wnt/frizzled signaling pathway via $\beta$-catenin leads to the activation of a plethora of Wnt target genes (http://ww w.stanford.edu/group/nusselab/cgi-bin/wnt/target_genes), the majority of which are tissue- or cell-specific (Clevers and Nusse, 2012). On the other hand, the non-canonical Wnt/ frizzled pathways are $\beta$-catenin independent. While the 2 pathways have distinct functions, they share 3 fundamental components: the Wnt ligands, the frizzled receptors, and the low-density lipoprotein receptor-related proteins (LRP). Wnts are highly conserved glycoproteins that are expressed in nearly all cell types (MacDonald et al., 2009). To date, 19 different Wnt members have been identified in mammals (Mikels and Nusse, 2006). Frizzleds are the corresponding receptors of Wnts. They are 7-transmembrane receptors and currently 10 different frizzled receptors have been identified in mammals (Povelones and Nusse, 2005). Lastly, LRPs are co-receptors essential for functional signaling activity of the pathway (mostly the $\beta$-catenin dependent) and the main LRP family members are LRP5 and LRP6 (He et al., 2004). For more details on the various components of the canonical and noncanonical Wnt/frizzled signaling pathways, the reader is referred to recent reviews of Rao and Kuhl (2010) and Clevers and Nusse (2012).

\section{The Wnt/frizzled signaling pathway as a target to prevent HF post-MI}

It is well established that Wnt signaling plays a crucial role in cardiogenesis and especially in the formation of the myocardium (Eisenberg and Eisenberg, 2006). Almost all frizzled members have been identified in the healthy heart tissue but the signaling in the adults is silent (Koval et al., 2011). However, the Wnt/frizzled cascade is reactivated (Frizzled-1 and Frizzled-2 receptors) in various pathologic conditions, such as in wound healing after MI (Blankesteijn et al., 1997), in cardiac hypertrophy and HF, in atherosclerosis etc (van de Schans et al., 2008), where fetal genes are reexpressed (Kuwahara and Nakao, 2011). Hence, lately more and more attention is drawn to the Wnt/frizzled signaling and whether it can be of interest in the search for novel pharmacologic treatments following $\mathrm{MI}$, in order to prevent adverse cardiac remodeling and HF. Potential levels of intervention on the Wnt signaling pathway are outside the cell (cell membrane, in order to prevent/promote the formation of the Wnt/ frizzled/LRP complex), in the cell cytoplasm (affecting the destruction complex), or within the nucleus (modulating the effect of $\beta$-catenin on the gene transcription) and have been discussed in this order. For an overview of the studies included in this review, the reader is referred to Table 1 and Fig. 2.

\section{Interventions in Wnt signaling after MI: Outside the cell membrane}

Secreted frizzled related proteins (sFRPs) are molecules that directly bind to Wnts, preventing Wnt/frizzled interaction and hence the activation of Wnt signaling in the cell (Bovolenta et al., 2008). The group of Duplaa investigated the role of sFRPs in the post-MI healing process in FzdA (or sFRP-1) overexpressing transgenic mice. They observed a reduction in the infarct size (days 2, 15 and 30 post-MI) and of the cardiac rupture incidence (days 4-5 post-MI), while cardiac function was improved (Barandon et al., 2003). A later study of Barandon et al. suggested that the beneficial effects of SFRP-1 were mediated via the $\mathrm{Wnt} / \mathrm{Ca}^{2+}$ pathway, leading to an inhibition of IL-6, IL-1 $\beta$, and IL-8 (all pro-inflammatory genes) expression in neutrophils. In a follow-up study, in which sFRP-1-overexpressing bone marrow-derived cells (BMCs) were transplanted into the infarcted myocardium, the infiltration of neutrophils in the scar was decreased. Neutrophil infiltration is associated not only with a reduced expression of IL-6 (pro-inflammatory cytokine) and boosted expression of IL-10 (anti-inflammatory cytokine), but also with a reduced incidence of cardiac rupture (Barandon et al., 2011).

Alfaro et al. studied genetically modified mesenchymal stem cells (MSCs) that are shown to overexpress sFRP-2. After a single administration of these MSCs to the infarct area of mice, infarct size was reduced and cardiac function was substantially improved 30 days post-MI (Alfaro et al., 2008). Furthermore, the same group showed that sFRP-2 reduces MSCs apoptosis and this might also be implicated in the SFRP-2 mediated beneficial effects after MI. The authors suggest that this effect on apoptosis is mediated via two separate systems that do not seem to crosstalk, the Wnt/ $\beta$-catenin and the bone morphogenic protein (BMP)-mediated pathways (Alfaro et al., 2010). He et al. also demonstrated a positive effect of SFRP-2 in rats after MI. Recombinant sFRP-2 protein was injected as a single dose ( $4 \mu \mathrm{g}$ of protein) directly into the infarcted area of rats, 2 days post-MI . Recombinant sFRP-2 affected collagen I deposition and substantially reduced the fibrosis 14 days after MI induction, while it improved cardiac function 4 weeks after 
A

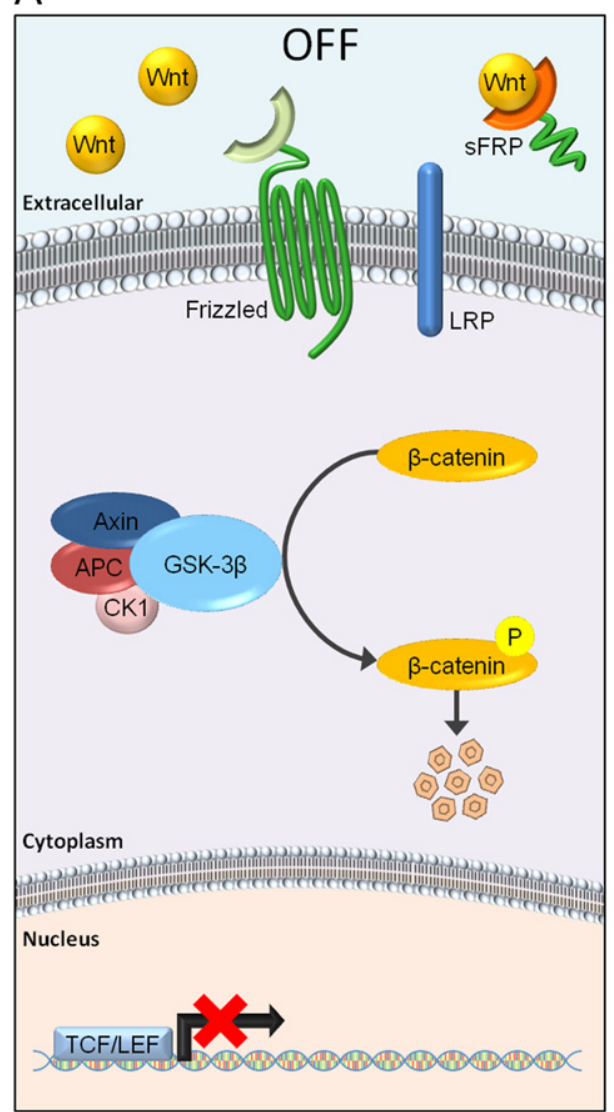

B

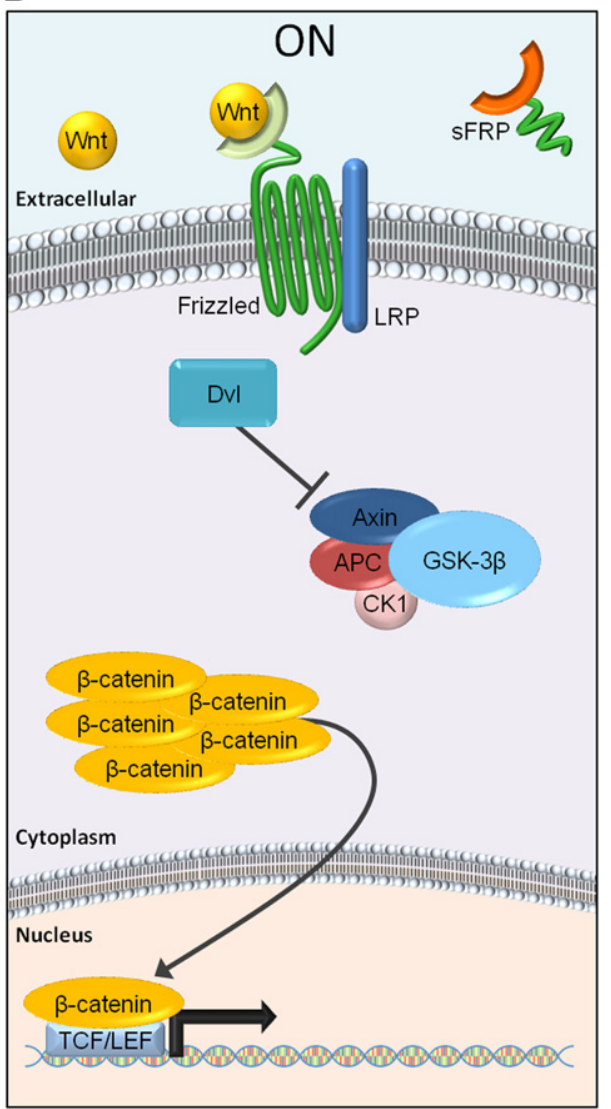

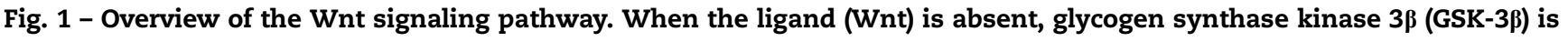
stabilized by several factors, including the adenomatous polyposis coli (APC), casein kinase 1 (CK1) and Axin, which form together the so called "destructive complex". Activated GSK-3 $\beta$ phosphorylates $\beta$-catenin and initiates its degradation. In this way, $\beta$-catenin is prevented from entering the nucleus and gene transcription is hindered (A- "OFF mode"). sFRPs (soluble frizzled related proteins) can also act as inhibitors, by binding Wnt and hence not allowing it to act on the frizzled receptor. In contrast, if Wnt binds to the frizzled receptor and the low-density lipoprotein receptor-related proteins (LRP) co-receptor, the Wnt-frizzled-LRP complex activates the Dishevelled (Dvl) protein which dissolutes the "destructive complex", allowing the translocation of $\beta$-catenin into the nucleus. In this cell compartment, $\beta$-catenin binds to T-cell factor/Lymphoid enhancer factor (TCF/LEF) proteins and activates the transcription of Wnt target genes (B- "ON mode"; Kikuchi et al., 2007; Kimelman and $\mathrm{Xu}$, 2006).

MI, compared with controls. Nevertheless, this antifibrotic effect of sFRP-2 does not seem to be mediated via Wnt signaling pathway but via BMP1 (a tolloid-like metalloproteinase; He et al., 2010). On the other hand, a study by Kobayashi et al. demonstrated exactly opposite effects of sFRP-2. sFRP-2 knockout (KO) mice had less matured collagen, substantially increased ejection fraction (EF; almost equal to that of sham animals) and improved cardiac function, compared with sFRP-2 wild type (WT) animals 14 days post-MI. Again, these anti-fibrotic effects do not appear to be directly connected to a Wnt/frizzled activation, but rather are the result of an indirect BMP1 effect (Kobayashi et al., 2009). Nevertheless, the majority of the studies on sFRPs indicate a beneficial effect of the blockade of Wnt/frizzled signaling in cardiac remodeling post-MI.

In vitro studies conducted by our group showed that Wnt/ frizzled signaling manipulations have direct effects on (myo)fibroblast migration and differentiation, the presence of which in the infarct area is crucial for the wound healing
post-MI . Different combinations of Wnts (Wnt3a or Wnt5a) and frizzleds (Fzd-1 or Fzd-2) can have opposite effects on the (myo)fibroblast. The combinations of Fzd-2/Wnt3a and Fzd-1/ Wnt5a inhibited the differentiation of cardiac fibroblasts immortalized with telomerase (CFIT), whereas the opposite effect was demonstrated for the combinations of Fzd-2/ Wnt5a and Fzd-1/Wnt3a. In addition, CFIT migration was inhibited with all possible Fzd/Wnt combinations (Laeremans et al., 2010). When UM206 (a peptide fragment of Wnt5a) was used in the same cells, it was shown to possess antagonistic properties for the Fzd-2 receptor and to completely block the inhibitory effects of Wnt3a in the CFIT differentiation and migration. This formed the basis for the in vivo studies in a mouse MI model. Treatment with UM206 for 5 weeks immediately after MI lead to suppression of the infarct area, an increase of the wall thickness, a substantial improvement of the cardiac function parameters, and the complete prevention of HF-related mortality in the UM206-treated mice, compared with a $30 \%$ mortality of the saline-treated controls. 
Table 1 - Overview of the latest studies targeting the Wnt-signaling pathway after MI.

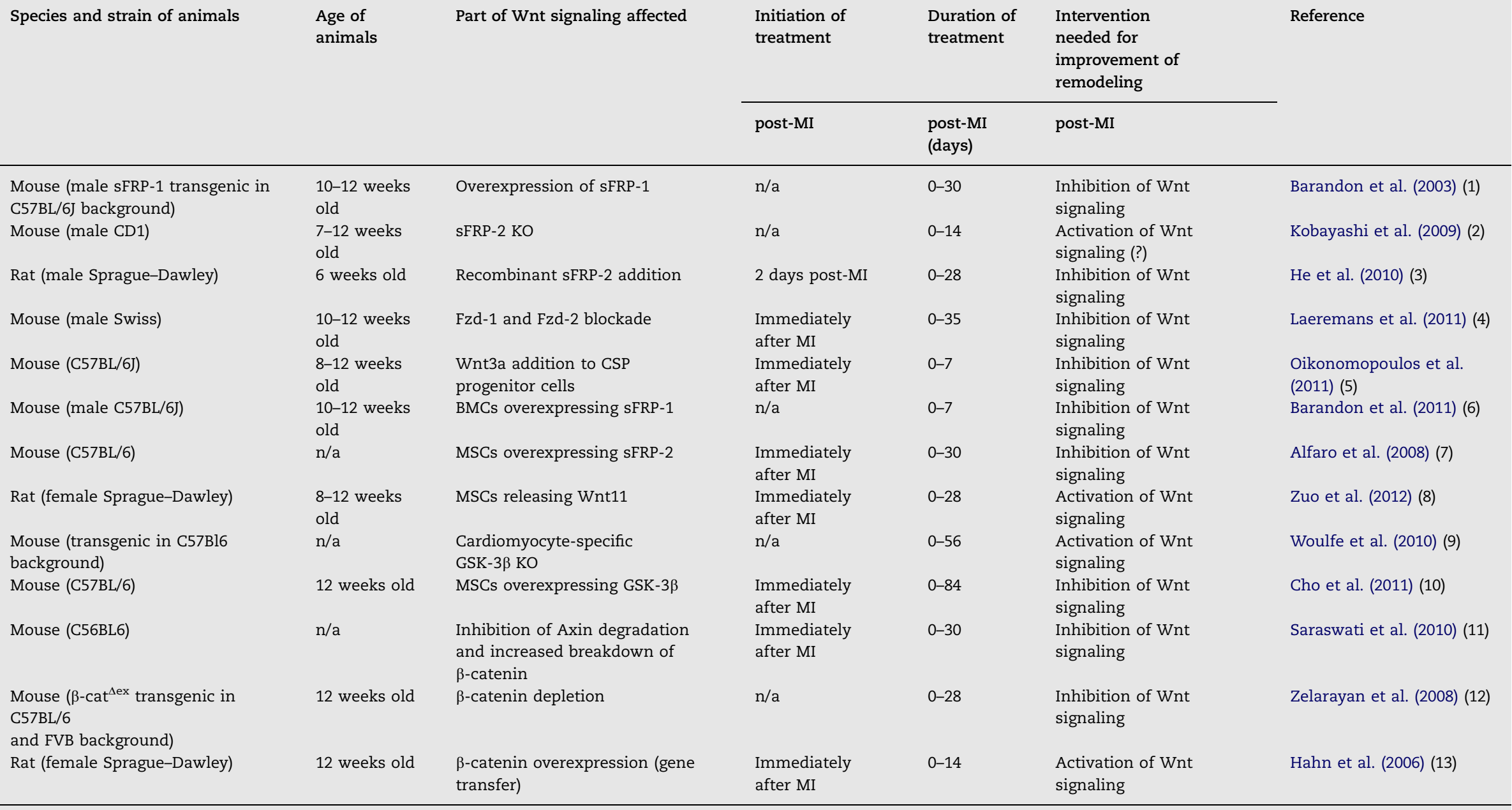

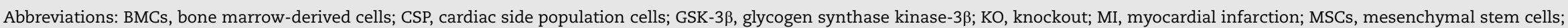
sFRP, soluble frizzled related proteins. 
A

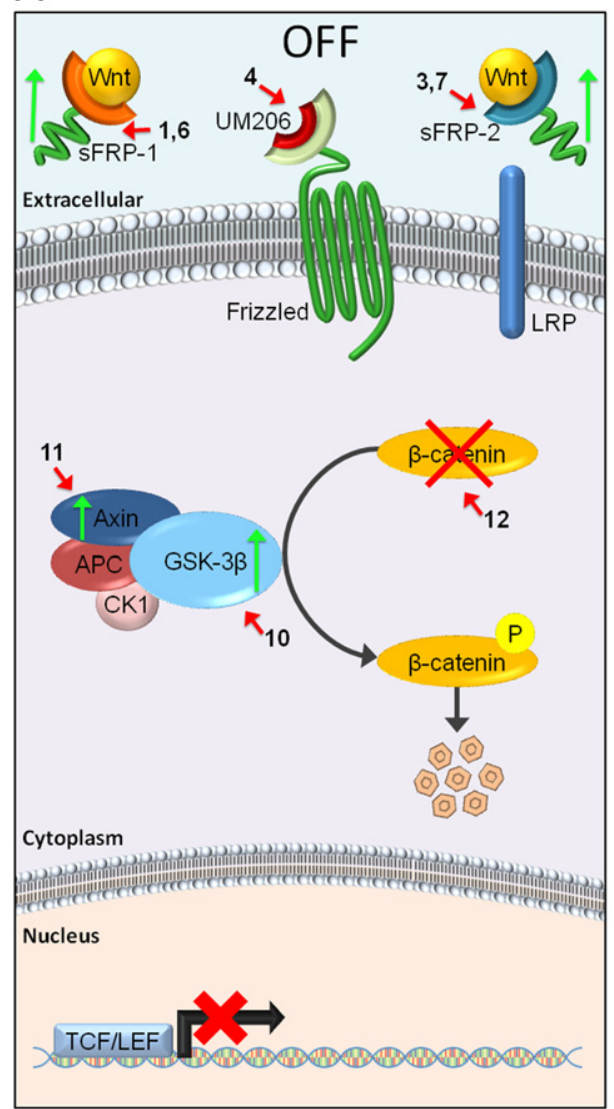

B

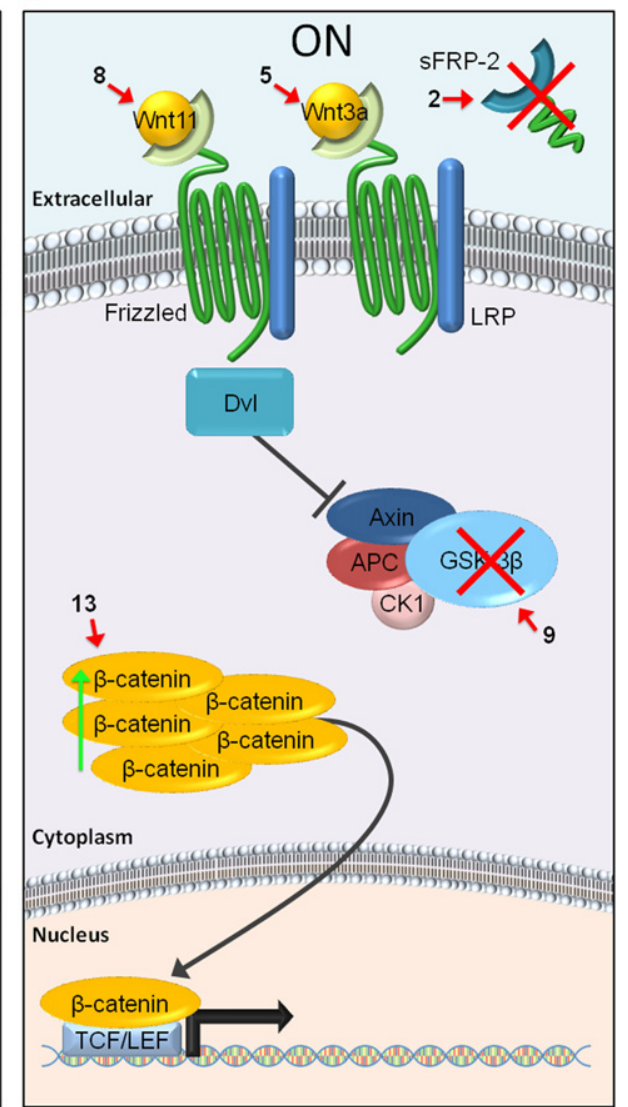

Fig. 2 - Site of action of the several approaches targeting the Wnt/frizzled signaling pathway after MI. Factors acting as inhibitors of the Wnt/frizzled signaling pathway (A- "OFF mode") and factors acting as inducers, activating the pathway (B- “ON mode"). For the numbering of each study involved in the targeting of the Wnt/frizzled signaling pathway, please refer to Table 1 (far right column). Abbreviations: APC, adenomatous polyposis coli; CK1, casein kinase 1; Dvl, dishevelled;

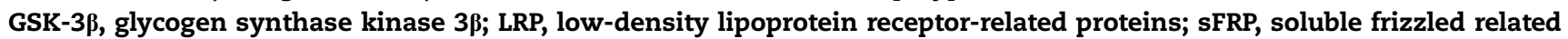
proteins; TCF/LEF, T-cell factor/Lymphoid enhancer factor.

Myofibroblast counts in the UM206-treated group were greatly increased, which showed that targeting myofibroblasts via the Wnt/frizzled signaling can be a promising therapeutic approach in the prevention of HF post-MI (Laeremans et al., 2011).

A recent study by Oikonomopoulos et al. established a direct inhibitory effect of Wnt3a in cardiac side population (CSP) cell proliferation in vitro, which appears to be mediated via cell cycle regulation and involves insulin growth factor binding protein 3 (IGFBP3). Moreover, when Wnt3a or IGFBP3 was injected into the injured MI area, Wnt-related genes were up-regulated and CSP numbers in the infarcted area were suppressed, leading to increased LV remodeling and a worsened cardiac function (Oikonomopoulos et al., 2011). Lastly, the group of Zuo developed MSCs that overexpress Wnt11. Female rats were subjected to MI and immediately afterwards the $\mathrm{MSC}^{\mathrm{Wnt11}}$ were transplanted in the periinfarct area of the rats. It was demonstrated that the infarct size and the LV anterior wall thickness were substantially reduced 4 weeks post-MI in the animals that were transplanted with MSC ${ }^{\text {Wnt11 }}$ compared to the controls. The authors suggest that this beneficial effect of the MSC ${ }^{\text {Wnt11 }}$ could be due to increased transdifferentiation of cardiomyocytes or due to an effect of Wnt11 during the acute ischemic attack phase; however they could not rule out paracrine factors (that are also released by the $\mathrm{MSC}^{\mathrm{Wnt11}}$ ) also playing an important role in the cardioprotective effect (Zuo et al., 2012). It has to be noted that interventions targeting components on the outside of the cell membrane (frizzled, LRP) are probably more easily accessible, offering a pharmacokinetic advantage over interventions on intracellular targets.

\section{Interventions in Wnt signaling after MI: In the cytoplasm}

Glycogen synthase kinase $3 \beta$ (GSK-3 $\beta$ ) is the most important cytoplasmic component of the canonical Wnt pathway. Woulfe et al. studied cardiomyocyte-specific GSK-3 $\beta$ KO mice that were subjected to MI. In these $\mathrm{KO}$ mice ventricular dilatation was substantially decreased and cardiac function significantly restored at 4 and 8 weeks post-MI, implying a protective effect of the deletion of GSK-3 $\beta$ (Woulfe et al., 2010). Because of the fact that GSK-3 $\beta$ KO affected only the cardiomyocytes, potential effects of Wnt signaling on (myo)fibroblasts cannot be ruled out. This is illustrated by the 
observation that transplantation of MSCs that overexpress GSK-3 $\beta$ beneficially modified cardiac function and survival post-MI. Nevertheless, this effect might be a result of the actions of GSK-3 $\beta$ on the Akt pathway and - possibly - not on the Wnt signaling cascade (Cho et al., 2011).It has to be noted here that a number of GSK-3 inhibitors have been identified (Meijer et al., 2004) and hence it would be challenging to investigate their potential effects after MI.

In addition, Saraswati et al. (2010) studied pyrvinium, a potent molecule known to prevent Axin degradation and to promote the breakdown of $\beta$-catenin (hence acting as a Wnt signaling inhibitor). After a single administration of the molecule (since its repeated administration increased mortality) in the border zone of the infarct, the treated mice demonstrated an improved LV remodeling 30 days after MI. Furthermore, the authors suggest that the beneficial effects of pyrvinium after MI are attributed to the inhibition of Wnt/ frizzled signaling in cardiomyocytes.

\section{Interventions in Wnt signaling after MI: In the nucleus}

Various groups have focused on the modulation of more downstream parts of the canonical Wnt signaling pathway and have targeted $\beta$-catenin in MI animal models. A multicenter team examined infarct healing in $\beta$-catenin depleted and $\beta$-catenin stabilized transgenic mice. In $\beta$-catenin depleted mice, mortality was reduced at 2 and 4 weeks post-MI, and infarct size was suppressed 4 weeks after MI, whereas mortality of the $\beta$-catenin stabilized mice was increased. The authors suggest that the $\beta$-catenin deletion increases the differentiation of resident cardiac progenitor cells, which in turn exhibit a beneficial effect on LV remodeling after the infarction (Zelarayan et al., 2008).

Contrasting data were reported by the group of Hahn. They constructed an adenoviral vector expressing triple mutant $\beta$-catenin which was injected in the infarcted area of a rat MI model. This $\beta$-catenin gene transfer lead to improved LV end diastolic/end systolic measurements, as well as a suppression of the infarcted area compared to control rats -7 and 14 days post-MI- with apoptosis suppression and increased myofibroblast differentiation being the potential mechanisms. Nevertheless, the authors reported an increase in the cardiomyocyte hypertrophy (which can lead to negative outcomes, especially in the early stages post-MI; Hahn et al., 2006), although it included only female rats which are known to react differently from males after MI (Jain et al., 2002).

Lastly, Hippo is a signaling pathway playing an important role in apoptosis as well as cell proliferation and its most downstream effector is Yap. The group of Martin proved that the Hippo pathway can interact inside the nucleus with the canonical Wnt/ $\beta$-catenin pathway. Furthermore, they demonstrated in vitro that Hippo signaling can suppress the $\beta$-catenin/Yap interaction in differentiating cardiomyocytes, thus leading to decreased proliferation of cardiomyocytes and so a decreased heart size. This preliminary finding could form the basis of more research on how a Hippo-blocking agent could induce the proliferation of cardiomyocytes following MI (Heallen et al., 2011).

\section{Conclusions}

The therapeutic options for treatment of patients that have suffered from MI have improved substantially over the last 3 decades. However, current pharmacologic therapy cannot stop cardiac remodeling and its progression to HF, but mainly suppresses the symptoms. Hence, it is apparent that novel agents are urgently required in order to develop more efficient strategies against the development of HF, post-MI. The Wnt/frizzled signaling cascade has a crucial role in the remodeling after $\mathrm{MI}$ and the latest research suggests an exciting field that we have only begun to explore. Nevertheless, several discrepancies are demonstrated between the different studies, most of them implying a beneficial effect after inhibition of the Wnt signaling, while others support the activation of the cascade. The reasons for these conflicting data are not fully clear but the use of different species (mice or rats) and strains and the utilization of variable treatment regimens (starting at various points post-MI and continuing for different lengths of time) are likely to contribute. Moreover, several of the aforementioned studies use diverse genetically expressed stem cell types, which are known to have different properties and sometimes disappointing yields of cellular reprogramming (Murry and $\mathrm{Pu}$, 2011). Furthermore - to the knowledge of the authors - no clinical trials have been conducted thus far, making it more difficult to extrapolate the results of the experimental animal studies. The majority of the current research studies supports the inhibition of Wnt signaling theory to be the most prevalent (possibly in the same context that $\beta$-adrenoceptor blockade and RAAS blockade is also beneficial), however more research is required in order to elucidate the actual mechanisms by which Wnt, frizzled and their downstream molecules are involved in the remodeling process. We believe that the Wnt/frizzled signaling pathway may offer a novel therapeutic approach for modulating cardiac repair after MI and in prevention of HF.

\section{Acknowledgments}

The financial support for this research line by the Department of Economic Affairs of The Netherlands (BSIK Grant 03033) is gratefully acknowledged.

\section{R E F E R E N C E S}

Alfaro MP, Pagni M, Vincent A, Atkinson J, Hill MF, Cates J, et al. The Wnt modulator sFRP2 enhances mesenchymal stem cell engraftment, granulation tissue formation and myocardial repair. Proceedings of the National Academy of Sciences of the United States of America 2008;105:18366-71.

Alfaro MP, Vincent A, Saraswati S, Thorne CA, Hong CC, Lee E, et al. sFRP2 suppression of bone morphogenic protein (BMP) and Wnt signaling mediates mesenchymal stem cell (MSC) self-renewal promoting engraftment and myocardial repair. Journal of Biological Chemistry 2010;285:35645-53.

Barandon L, Casassus F, Leroux L, Moreau C, Allieres C, Lamaziere JM, et al. Secreted frizzled-related protein-1 
improves postinfarction scar formation through a modulation of inflammatory response. Arteriosclerosis, Thrombosis, and Vascular Biology 2011;31:e80-87.

Barandon L, Couffinhal T, Ezan J, Dufourcq P, Costet P, Alzieu P, et al. Reduction of infarct size and prevention of cardiac rupture in transgenic mice overexpressing FrzA. Circulation 2003;108:2282-9.

Blankesteijn WM, Essers-Janssen YP, Verluyten MJ, Daemen MJ, Smits JF. A homologue of Drosophila tissue polarity gene frizzled is expressed in migrating myofibroblasts in the infarcted rat heart. Nature Medicine 1997;3:541-4.

Bovolenta P, Esteve P, Ruiz JM, Cisneros E, Lopez-Rios J. Beyond Wnt inhibition: new functions of secreted Frizzled-related proteins in development and disease. Journal of Cell Science 2008;121:737-46.

Bui AL, Horwich TB, Fonarow GC. Epidemiology and risk profile of heart failure. Nature Reviews Cardiology 2011;8:30-41.

Cho J, Zhai P, Maejima Y, Sadoshima J. Myocardial injection with GSK-3beta-overexpressing bone marrow-derived mesenchymal stem cells attenuates cardiac dysfunction after myocardial infarction. Circulation Research 2011;108:478-89.

Cleutjens JP, Blankesteijn WM, Daemen MJ, Smits JF. The infarcted myocardium: simply dead tissue, or a lively target for therapeutic interventions. Cardiovascular Research 1999;44:232-41.

Clevers H, Nusse R. Wnt/beta-catenin signaling and disease. Cell 2012;149:1192-205.

Daskalopoulos EP, Janssen BJ, Blankesteijn WM. Myofibroblasts in the infarct area: concepts and challenges. Microscopy and Microanalysis 2012;18:35-49.

Eisenberg LM, Eisenberg CA. Wnt signal transduction and the formation of the myocardium. Developmental Biology 2006; 293:305-15.

Gajarsa JJ, Kloner RA. Left ventricular remodeling in the postinfarction heart: a review of cellular, molecular mechanisms, and therapeutic modalities. Heart Failure Reviews 2011;16: 13-21.

Hahn JY, Cho HJ, Bae JW, Yuk HS, Kim KI, Park KW, et al. Betacatenin overexpression reduces myocardial infarct size through differential effects on cardiomyocytes and cardiac fibroblasts. Journal of Biological Chemistry 2006;281:30979-89.

He W, Zhang L, Ni A, Zhang Z, Mirotsou M, Mao L, et al. Exogenously administered secreted frizzled related protein 2 (Sfrp2) reduces fibrosis and improves cardiac function in a rat model of myocardial infarction. Proceedings of the National Academy of Sciences of the United States of America 2010;107:21110-5.

He X, Semenov M, Tamai K, Zeng X. LDL receptor-related proteins 5 and 6 in Wnt/beta-catenin signaling: arrows point the way. Development 2004;131:1663-77.

Heallen T, Zhang M, Wang J, Bonilla-Claudio M, Klysik E, Johnson $\mathrm{RL}$, et al. Hippo pathway inhibits Wnt signaling to restrain cardiomyocyte proliferation and heart size. Science 2011;332: 458-61.

〈http://www.stanford.edu/group/nusselab/cgi-bin/wnt/target_ genes $\rangle$.

Jain M, Liao R, Podesser BK, Ngoy S, Apstein CS, Eberli FR. Influence of gender on the response to hemodynamic overload after myocardial infarction. American Journal of Physiology: Heart and Circulatory Physiology 2002;283:H2544-2550.

Katz AM, Konstam MA. Heart failure: pathophysiology, molecular biology, and clinical management, 2nd edition Philadelphia: Lippincott Williams; 2009.

Kikuchi A, Yamamoto H, Kishida S. Multiplicity of the interactions of Wnt proteins and their receptors. Cellular Signalling 2007;19:659-71.

Kimelman D, Xu W. Beta-catenin destruction complex: insights and questions from a structural perspective. Oncogene 2006; 25:7482-91.
Kobayashi K, Luo M, Zhang Y, Wilkes DC, Ge G, Grieskamp T, et al. Secreted Frizzled-related protein 2 is a procollagen $C$ proteinase enhancer with a role in fibrosis associated with myocardial infarction. Nature Cell Biology 2009;11:46-55.

Koval A, Purvanov V, Egger-Adam D, Katanaev VL. Yellow submarine of the Wnt/Frizzled signaling: submerging from the $G$ protein harbor to the targets. Biochemical Pharmacology 2011; 82:1311-9.

Kuwahara K, Nakao K. New molecular mechanisms for cardiovascular disease:transcriptional pathways and novel therapeutic targets in heart failure. Journal of Pharmacological Sciences 2011;116:337-42.

Laeremans H, Hackeng TM, van Zandvoort MA, Thijssen VL, Janssen BJ, Ottenheijm HC, et al. Blocking of frizzled signaling with a homologous peptide fragment of Wnt3a/Wnt5a reduces infarct expansion and prevents the development of heart failure after myocardial infarction. Circulation 2011;124:1626-35.

Laeremans H, Rensen SS, Ottenheijm HC, Smits JF, Blankesteijn WM. Wnt/frizzled signalling modulates the migration and differentiation of immortalized cardiac fibroblasts. Cardiovascular Research 2010;87:514-23.

MacDonald BT, Tamai $\mathrm{K}, \mathrm{He} \mathrm{X}$. Wnt/beta-catenin signaling: components, mechanisms, and diseases. Developmental Cell 2009;17:9-26.

McMurray JJ, Pfeffer MA. Heart failure. Lancet 2005;365:1877-89.

Meijer L, Flajolet M, Greengard P. Pharmacological inhibitors of glycogen synthase kinase 3. Trends in Pharmacological Sciences 2004;25:471-80.

Mikels AJ, Nusse R. Wnts as ligands: processing, secretion and reception. Oncogene 2006;25:7461-8.

Murry CE, Pu WT. Reprogramming fibroblasts into cardiomyocytes. New England Journal of Medicine 2011;364:177-8.

Nusse R, Varmus HE. Many tumors induced by the mouse mammary tumor virus contain a provirus integrated in the same region of the host genome. Cell 1982;31:99-109.

Oikonomopoulos A, Sereti KI, Conyers F, Bauer M, Liao A, Guan J, et al. Wnt signaling exerts an antiproliferative effect on adult cardiac progenitor cells through IGFBP3. Circulation Research 2011;109:1363-74.

Povelones M, Nusse R. The role of the cysteine-rich domain of Frizzled in Wingless-Armadillo signaling. EMBO Journal 2005; 24:3493-503.

Rao TP, Kuhl M. An updated overview on Wnt signaling pathways: a prelude for more. Circulation Research 2010;106:1798-806.

Roger VL, Go AS, Lloyd-Jones DM, Adams RJ, Berry JD, Brown TM, et al. Heart disease and stroke statistics-2012 update: a report from the American Heart Association. Circulation 2012;125: e2-220.

Saraswati S, Alfaro MP, Thorne CA, Atkinson J, Lee E, Young PP. Pyrvinium, a potent small molecule Wnt inhibitor, promotes wound repair and post-MI cardiac remodeling. PLoS One 2010;5:e15521.

van de Schans VA, Smits JF, Blankesteijn WM. The Wnt/frizzled pathway in cardiovascular development and disease: friend or foe? European Journal of Pharmacology 2008;585:338-45.

Woulfe KC, Gao E, Lal H, Harris D, Fan Q Vagnozzi R, et al. Glycogen synthase kinase-3beta regulates post-myocardial infarction remodeling and stress-induced cardiomyocyte proliferation in vivo. Circulation Research 2010;106:1635-45.

Zelarayan LC, Noack C, Sekkali B, Kmecova J, Gehrke C, Renger A, et al. Beta-catenin downregulation attenuates ischemic cardiac remodeling through enhanced resident precursor cell differentiation. Proceedings of the National Academy of Sciences of the United States of America 2008;105:19762-7.

Zuo S, Jones WK, Li H, He Z, Pasha Z, Yang Y, et al. Paracrine effect of Wnt11-overexpressing mesenchymal stem cells on ischemic injury. Stem Cells and Development 2012;21: 598-608. 